\title{
Objetivos educacionais de um mestrado profissional em saúde coletiva: avaliação conforme a taxonomia de Bloom
}

\begin{abstract}
Walner Mamede ${ }^{1}$
Gardênia S. Abbad²

\section{Resumo}

Os mestrados profissionais são um instrumento de uma política maior de flexibilização da pós-graduação brasileira. Como tais, visam a uma aproximação entre o mundo acadêmico e o mundo do trabalho em geral. Para tanto, necessitam romper as barreiras que separam esses dois mundos e uma das estratégias concentra-se na prática didática, a qual está intimamente relacionada com os objetivos educacionais traçados e que a orientam. Sendo a falta de clareza dos objetivos uma causa comum de insucessos na sala de aula, o presente trabalho buscou avaliar os objetivos educacionais de um mestrado profissional em saúde coletiva, de uma universidade federal brasileira. Para o estudo proposto, utilizamos como método de pesquisa a análise documental e como referência teórica os princípios da taxonomia de Bloom. Concluímos que o caso estudado necessita aprimorar a construção de seus objetivos educacionais, a fim de permitir um melhor direcionamento de suas práticas pedagógicas, contribuindo para uma efetiva aproximação ensino-serviço, no âmbito da saúde coletiva, sem o que tenderá a reproduzir a perspectiva ideológica dos mestrados acadêmicos, na qual a aplicabilidade social do conhecimento produzido, a despeito de sua relevância científica, é contingente e condicionada pela capacidade individual do egresso e não por sua definição como um indicador de resultado do próprio programa.
\end{abstract}

\section{Palavras-chave}

Ensino na saúde - Mestrado profissional - Avaliação de objetivos educacionais.

\section{Educational goals in a professional master degree in Public Health: assessment according Bloom's Taxonomy}

\section{Abstract}

The professional master programs are an instrument of a more comprehensive policy intended to make graduate studies in Brazil more flexible. As such, they have the purpose

1- Coordenação de Aperfeiçoamento de Pessoal de Nível Superior (Capes), Brasília, DF, Brasil. Contato: walner.mamede@capes.gov.br; walnermamede@gmail.com.

2- Universidade de Brasília, Brasília, DF, Brasil. Contato: gardenia.abbad@gmail.com

DOl: http://dx.doi.org/10.1590/S1678-4634201710169805 
of bringing academia closer to the world of labor in general. In order to do so, they need to break the barriers between these two worlds and one of the strategies focuses on didactic practice, which is closely related to and guided by educational objectives. Since the lack of clarity concerning objectives is a common cause of failure in the classroom teaching, this study sought to evaluate the educational objectives of a professional master's degree in Public Health provided by a Brazilian federal university. For the proposed study, we used the documentary analysis an theoretical framework was Bloom's Taxonomy principles. We concluded that the case in question needs to improve the definition of its educational objectives, in order to allow a better targeting of its pedagogical practices, to contribute to effectively bring teaching and service closer in the field of Public Health. Without that, it will tend to reproduce the ideological perspective of academic master programs, in which the social applicability of the knowledge produced, despite its scientific relevance, is contingent to and conditioned by the individual capacity of and not by its definition as an indicator of results of the program.

\section{Keywords}

Health Education - Professional master's degree - Evaluation of educational objectives.

\section{Introdução}

Em 1995, a política de flexibilização da pós-graduação brasileira foi instituída pelo Conselho Superior da Coordenação de Aperfeiçoamento de Pessoal de Nível Superior Capes (BRASIL, 2005), sendo formalizada pela Portaria Capes n. 47 (BRASIL, 1995) e reafırmada por sucessivos instrumentos legais até o atual Plano Nacional de Pós-Graduação - PNPG (BRASIL, 2010) em busca de atender demandas nacionais já identificadas desde o Parecer n. 977 (BRASIL, 1965), de Newton Sucupira. Consoante Barros, Valentim e Melo (2005) e Melo e Oliveira (2005), mesmo antes da instituição formal e sistemática de ações governamentais destinadas à flexibilização da pós-graduação no Brasil, várias instituições de ensino superior implantaram cursos de mestrado com perfil profissionalizante, muitas vezes de forma não explícita ao longo dos últimos cinquenta anos, antecedendo a materialização legal dos mestrados profissionais (MP) pela Portaria Capes n. 47 (BRASIL, 1995). Entretanto, existe grande diversidade de perfis e entendimentos sobre como deve ser estruturado um curso dessa natureza, ainda hoje (QUARESMA; MACHADO, 2014), uma vez que isso depende das vivências concretas, expectativas e interesses do coletivo responsável pela criação do programa.

Subvertendo a ideia do ócio ou scholé que, consoante Arendt (2010), é considerada tão cara à produção do conhecimento acadêmico, o mestrado profissional (MP) institui a necessidade do debate público e ampliado sobre questões, a princípio, restritas ao meio acadêmico e apresenta para a universidade a vita activa como origem e destino desse conhecimento, possibilitando o que Ribeiro (2005) considera o resgate de uma dívida 
social, não sem provocar levantes contra as possibilidades que isso representa frente ao mercado e ao receio de submissão da universidade às suas diretrizes (SILVEIRA; PINTO, 2005; MELO; OLIVEIRA, 2005; OLIVEIRA; VELHO, 2009; BENTO, 2014). 0 espaço público é, assim, convocado pelo MP quando este se propõe a trazer para o seio da universidade demandas de caráter social e a levar de forma maciça e intencional para a sociedade conhecimentos antes restritos ao mundo acadêmico (RIBEIR0, 2010).

Na busca de efetivação das metas estabelecidas para um mestrado profissional, além da cumplicidade entre a universidade e a entidade demandante da qualificação, como preveem as diretrizes políticas expressas na Portaria Capes n. 17 (BRASIL, 2009), é necessário, ainda, que as próprias estratégias de ensino, avaliação e seleção de conteúdos sejam modificadas (QUARESMA; MACHAD0, 2014; MAMEDE, 2015), denotando um confronto entre o paradigma educacional predominante e o exigido para uma aplicação concreta do conhecimento científico e técnico com a eficiência e efetividade que se espera, atendendo, inclusive, aos critérios de mérito e valor trazidos por Scriven (1991).

Nesse sentido, percebemos um ponto de encontro entre a proposta do MP e as demandas formativas do Sistema Único de Saúde - SUS (OLIVEIRA, 1996; ROSA; LABATE, 2005; PEREIRA; LIMA, 2009). Assim, os mestrados profissionais em saúde coletiva (MPSC) surgiram como consequência da política de flexibilização da pósgraduação brasileira e com a finalidade de qualificar o sistema de saúde, por meio do empoderamento científico de suas equipes de trabalho, sendo esse o caso do programa de MPSC objeto do presente estudo.

É dentro desse contexto que se insere o presente trabalho. A análise documental buscou identificar o perfil dos objetivos educacionais, a fim de avaliar sua adequação teórica ao referencial aqui adotado, orientado pela taxonomia de Bloom (FERRAZ; BELHOT, 2010), e sua consistência com as metas da política de flexibilização da pósgraduação, bem como permitir a produção de material útil à análise de outros programas semelhantes e à reflexão sobre os mestrados profissionais em geral.

\section{Aspectos da taxonomia de Bloom}

Uma revisão da taxonomia de Bloom original, de 1956, foi realizada em 2001, agregando-lhe algumas alterações que a tornaram mais flexível quanto à hierarquia e modificaram os nomes das categorias do domínio cognitivo, de substantivos (Conhecimento, Compreensão, Aplicação, Análise, Síntese e Avaliação) para verbos de ação que expressassem melhor sua natureza, invertendo as duas últimas (Conhecer, Entender, Aplicar, Analisar, Avaliar e Criar). Embora tenha sido mantida a estrutura lógica original, a nova taxonomia assumiu um caráter mais processual e bidimensional, que passou a utilizar subcategorias como verbos no gerúndio e a valorizar as dimensões do conhecimento (efetivo ou factual, conceitual, procedural ou operacional, metacognitivo) na classificação dos objetivos. Dessa forma, um objetivo educacional completo deve conter: (a) um verbo de ação (cujo sujeito, via de regra, é o aluno) indicador de uma competência (conhecimentos, habilidades e atitudes) almejada e relacionado a um objeto direto ou indireto, que indica o (b) conteúdo sobre o qual se empreende a ação; (c) um 
referencial de avaliação representado, muitas vezes, por um verbo no gerúndio, que exprime, geralmente, o meio pelo qual se pretende expressar a competência objetivada e pode, algumas vezes, representar a circunscrição definida para alcance do fim, e (d) um parâmetro que indica uma referência qualitativa ou quantitativa para avaliação do sucesso de alcance do objetivo (SOSSAI, 1974; ABBAD et al., 2006; FERRAZ; BELHOT, 2010; MARTINEZ, MARTINEZ; TOLEDO, 2013; SILVA; MARTINS, 2014).

Talvez seja importante ressaltar que a presença do parâmetro e das condições quando esses são óbvios no contexto em que se processa a intervenção, sem possibilidades concorrentes que produzam dubiedades e, especialmente, quando nos referimos aos objetivos gerais aferentes (de ensino), não é sempre indispensável, mas facilita, sua compreensão pelos atores do processo, a estruturação das estratégias de implementação e sua avaliação futura, e que verbos no gerúndio, em inglês (origem da taxonomia de Bloom), aceitam tradução substantivada para o português. Assim, na nossa língua, um objetivo do tipo "aplicar elementos e índices econômicos, implementando avaliações dos serviços de saúde" teria o mesmo sentido que "aplicar elementos e índices econômicos, na implementação de avaliações dos serviços de saúde" ou, sendo mais flexível, "aplicar elementos e índices econômicos, por meio da implementação de avaliações dos serviços de saúde", que em inglês seria "apply elements and economic indices, implementing assessments of health services”. Assim, há que se atentar para o contexto discursivo geral ao se interpretar qual o sentido do verbo no gerúndio em um objetivo, sendo aconselhável, em português, evitar tais sintaxes, em razão da dificuldade de se interpretar se o sentido almejado é ter a implementação como circunscrição ou estratégia (meio) de aplicação.

Assim, na medida do possível, seguindo tais princípios da taxonomia de Bloom e buscando apoio em Abbad e colaboradores (2006), Rodrigues Jr. (2006), Mourão e Meneses (2012) e Zerbini e colaboradores (2012), o presente trabalho assume o pressuposto de que, nos objetivos, além das ações e seu conteúdo (fins), é desejável que estejam presentes elementos que indiquem as condições (circunscrição, meios, contexto) em que a ação deve se manifestar e os parâmetros quali/quantitativos pelos quais a ação será considerada um sucesso (critérios, normas, padrões) ${ }^{3}$. É interessante notar que Zerbini e colaboradores (2012) discriminam os objetivos de aprendizagem dos objetivos de desempenho, estando estes relacionados à aplicação do que fora aprendido na solução de problemas no ambiente de trabalho, indicando uma mudança no comportamento individual nesse ambiente. Ainda, Sossai (1974) chama a atenção para o fato de que a denominação objetivo psicomotor, atribuída por Bloom aos objetivos de ordem prática e aplicada, não encontra eco adequado dentro da educação em saúde, uma vez que a aplicação desejada nesse campo é maior que a simples observação de habilidades neuromotoras, é externa à sala de aula e não se resume à sua verificação nesses espaços. Além disso, alega que toda atividade humana é, em última análise, psicomotora, o que tornaria a expressão de Bloom ambígua e pouco precisa. Com isso, propõe a expressão objetivo ativo, reconhecendo suas limitações, mas entendendo ser ela mais ajustada aos objetivos da educação em saúde, qual seja, a adoção

3- A título de exemplo, um objetivo adequado seria: "Julgar boas práticas de atendimento, em cada órgão e entidade do SUS, conforme os padrões de qualidade do atendimento ao cidadão, por meio da observação da conduta dos trabalhadores". 
de práticas, o que, para além da habilidade neuromotora, pressupõe um conhecimento prévio e a atitude necessária para sua aplicação.

Dada a excessiva amplitude do termo psicomotor e à própria inexatidão do termo ativo, ambos apontados por Sossai (1974), e frente à aparente proximidade das proposições de Sossai (1974) com a solução apresentada por Zerbini e colaboradores (2012), a qual assimila, além das habilidades neuromotoras, conhecimentos e atitudes, portanto, competências, incorporamos as propostas de ambos e seguimos adiante, aqui propondo a divisão dos objetivos em aferentes e eferentes e assumindo a expressão objetivos de desempenho ou de aplicação acrescida do qualificativo eferentes, como uma síntese entre as expressões objetivo psicomotor e objetivo ativo. Ainda ecoando o pensamento de Sossai (1974), adotaremos a expressão sensório-motor como uma alternativa a psicomotor e ativo, mesmo que não isenta de críticas, para tentar designar o domínio dos objetivos relacionados com as habilidades neuromotoras.

Assim, no escopo do presente texto, devemos entender por aferência a propriedade de se focar os objetivos no ensino, com verbos mais gerais, tendo o programa e seu executor como sujeitos, que expressam suas intenções e expectativas quanto ao seu público ou aos seus produtos e ações, e o discente ou o contexto como destino (verbos de ação relacionados: qualificar, ensinar, possibilitar, disponibilizar, expor, educar, encorajar, estimular, constituir, apresentar, estabelecer, apoiar, discutir, viabilizar, favorecer, conscientizar, sensibilizar, provocar, mediar, garantir, orientar, auxiliar, fortalecer, aperfeiçoar, fornecer, capacitar, refletir, ressignificar, aproximar, vislumbrar e outros que remetam a ações que não se originem, exclusivamente, no discente). Os resultados de tais objetivos sobre o destinatário das ações são, muitas vezes, de difícil aferição, podendo almejar uma formação ética, política e filosófica, delineando os contornos gerais da intervenção, cujo detalhamento operacional é expresso por objetivos mais específicos (eferentes), focados em ações observáveis e mensuráveis.

Por eferência ${ }^{4}$ compreendemos a propriedade de se focar em ações cujo resultado se manifesta como competências nos cenários de ensino-aprendizagem (objetivos eferentes de aprendizagem) e no ambiente social ou de trabalho (objetivos eferentes de desempenho), se relacionando com verbos que indicam uma ação observável e mensurável no discente tido como sujeito e origem dessa ação (verbos de ação relacionados: reconhecer, identificar, interpretar, reelaborar, demonstrar, aplicar, avaliar, criar, lembrar, executar, produzir, solucionar, comparar, relacionar, apresentar, caracterizar, discutir, descrever, justificar, analisar, modificar, responder e os demais integrantes da taxonomia de Bloom que expressem ações observáveis do aluno, ainda que coincidentes com verbos aferentes.). Devemos ter claro que os verbos por si não são preditivos do tipo de objetivo, sendo necessário, às vezes, analisá-los à luz do contexto discursivo em que foram utilizados, contudo, são indícios mais ou menos seguros.

A relação entre aferência e eferência se dá, primariamente, no sentido da primeira para a segunda, tendo o contexto por moderador, ou seja, à semelhança dos sistemas

4- Vale mencionar que verbos referidos a comportamentos não observáveis, como conhecer, compreender, entender e outros que exijam aferição indireta, devem ser evitados, ainda que pertençam à taxonomia. 
orgânicos, os impulsos aferentes interferem sobre a resposta eferente, sob forte influência do ambiente que, modificado, produz feedbacks aferentes sobre o processo e seus sujeitos. Assim, objetivos, cujos verbos não expressam uma ação discente e sim uma ação sobre ou para ele, portanto aferentes, possuem a intenção de conduzir-lhe a uma ação que, se alcançada, expressa ou não em objetivos eferentes (objetivos implícitos), poderá imprimir modificações contextuais capazes de modular aqueles objetivos iniciais. Contudo, o alcance de expectativas por meio de diretrizes não declaradas dificulta a elaboração de estratégias didáticas adequadas e o próprio processo de aprendizagem (FERRAZ; BELHOT, 2010), sendo aceitáveis como parte de objetivos gerais (como são os de ensino), mas contraindicadas quando lidamos com objetivos mais específicos (como os de aprendizagem e desempenho).

\begin{abstract}
Muitos dos objetivos implícitos estão relacionados a aspectos cognitivos de alta abstração, em outras palavras, os educadores almejam que seus alunos atinjam um nível de maturidade de conhecimento muitas vezes incompatível com os objetivos declarados e com os procedimentos, estratégias e conteúdos utilizados e ministrados (FERRAZ; BELHOT, 2010, p. 422).
\end{abstract}

Os objetivos eferentes devem ser unifocais e dirigidos a resultados e não a processos (os quais serão avaliados à luz dos resultados), precisam ser individualmente relevantes para o objetivo aferente e, coletivamente, refletirem seu espírito, ainda que, muitas vezes, não possuam sentido individual completo. Dessa forma, um objetivo aferente ou eferente pode se localizar na dimensão cognitiva, sensório-motora ou afetiva, na dependência dos objetivos mais gerais do processo educacional.

Em síntese, objetivos cognitivos são defınidos por verbos que expressam a capacidade de o indivíduo apreender um conhecimento, reproduzi-lo ou recriá-lo em novo discurso próprio, aplicá-lo na solução de problemas concretos, decompô-lo em partes menores, para visualizar detalhes e relações, julgá-lo em seus significados e sentidos e enriquecê-lo, produzindo algo diferente, novo ou inovador. Os objetivos afetivos estariam relacionados com o desenvolvimento de atitudes, valores e crenças capazes de condicionar um comportamento, enquanto os sensório-motores se relacionam com o comportamento propriamente dito e com uma ação prática derivada de uma habilidade motora (SOSSAI, 1974; RODRIGUES JR., 2006). É desejável que um programa contenha esses três domínios como objetivos, organizados em uma sequência hierárquica, de forma que um seja prérequisito ao próximo da lista, estando nele contido (cumulatividade), segundo um eixo integrador (ABBAD et al., 2006). Contudo, consoante Sossai (1974), há que se questionar tal necessidade, uma vez que os objetivos afetivos são mensurados por meio dos outros dois, e os sensório-motores, restritos que são à sala de aula na taxonomia de Bloom, são ineficientes para se mensurar o comportamento nos postos de trabalho, sendo insuficiente a prática comum de inferir a possibilidade de modificações comportamentais a partir de objetivos e indicadores meramente cognitivos. Eis, entre outros, um motivo mais que suficiente para que os mestrados profissionais se comprometam com a avaliação e acompanhamento de seus egressos nos ambientes de serviço por meio de objetivos e indicadores de desempenho, para além dos cenários de ensino-aprendizagem. Além disso, os pressupostos taxonômicos (hierarquia, cumulatividade e eixo integrador) propostos 
inicialmente por Bloom e seus colaboradores vêm sendo alvo de questionamentos há longa data (RODRIGUES JR., 2006), tendo sido, ao menos em parte, relativizada a hierarquia pela revisão ocorrida em 2001 (FERRAZ; BELHOT, 2010), o que permite uma inversão das posições dos níveis Compreensão e Aplicação e dos níveis Síntese e Avaliação entre si, podendo ser considerado o nível Conhecimento como um processo à parte, na dependência do contexto e do perfil do público-alvo.

Os objetivos podem, ainda, quanto à natureza do conhecimento, ser classificados como (a) factuais, representando uma coleção de dados a se memorizar; (b) conceituais, referindo-se à interconexão dos dados memorizados, em modelos, heurísticas e novos conhecimentos indutivos e dedutivos; (c) operacionais, caracterizando o desenvolvimento de métodos, técnicas e de discernimento para seu uso; e (d) metacognitivos, referidos à capacidade de autoconhecimento e autopercepção da aprendizagem e das estratégias de sua construção, bem como de seus limites e potencialidades (FERRAZ; BELHOT, 2010; SILVA; MARTINS, 2014).

\section{Método de análise documental}

Tendo em mente a tensão entre ensino e aprendizagem na constituição do processo pedagógico e a definição de ensino trazida por Laburú, Arruda e Nardi (2003), para levantar os objetivos do programa avaliado, foi realizada análise do regulamento do programa, do plano de curso, dos planos de ensino e das dissertações concluídas pelos egressos do programa. Conforme as definições conceituais trazidas por Mamede (2016), extraímos os objetivos pedagógicos aferentes (focados no ensino e no professor) e eferentes de aprendizagem (focados no resultado acadêmico do aluno) e de desempenho (focados na aplicação pelo egresso, em situações de trabalho, das competências aprendidas), com atenção aos efeitos esperados e comportamentos por eles descritos, em conformidade com as prescrições teóricas trazidas por Ferraz e Belhot (2010), Mourão e Meneses (2012) e Zerbini e colaboradores (2012), focando-os no aluno e resgatando, do material analisado, as competências esperadas por aqueles que planejaram o curso.

Um primeiro passo para a análise documental foi a elaboração de uma matriz lógica heurística (MLH), apresentada na Figura 1, cuja concepção incorporou os princípios da técnica do modelo lógico (SOUZA, 2013; MOURÃ0; MENESES, 2012), se apoiou em pressupostos da avaliação trazidos por Sossai (1974), Hamblin (1978), Contandriopoulos e colaboradores (1997), Abbad e colaboradores (2006), Borges-Andrade (2002, 2006) e Zerbini e colaboradores (2012) e adotando as definições presentes em Mamede (2016), e foi constituída com os seguintes componentes: (1) caracterização do cenário (problemagerador e insumos); (2) caracterização de horizontes (retorno social, objetivos aferentes de ensino e objetivos eferentes de aprendizagem e desempenho); (3) caracterização de processos (procedimentos, estratégias, atividades, métodos e outras ações empreendidas); e (4) caracterização dos resultados (efeito imediato tangível/objetivo e intangível/subjetivo e efeito tardio primário e secundário). Cada um desses componentes foi definido dentro de três etapas sequenciais (ex-ante, in curso e ex-post) e dois planos (lógico, apresentando a lógica de organização da estrutura, e cronológico, apresentando a ordem de ocorrência das ações A, B e C e 1, 2, 3 e 4). 
Figura 1 - Matriz lógica heurística desenvolvida para planejamento e avaliação de intervenções educativas.

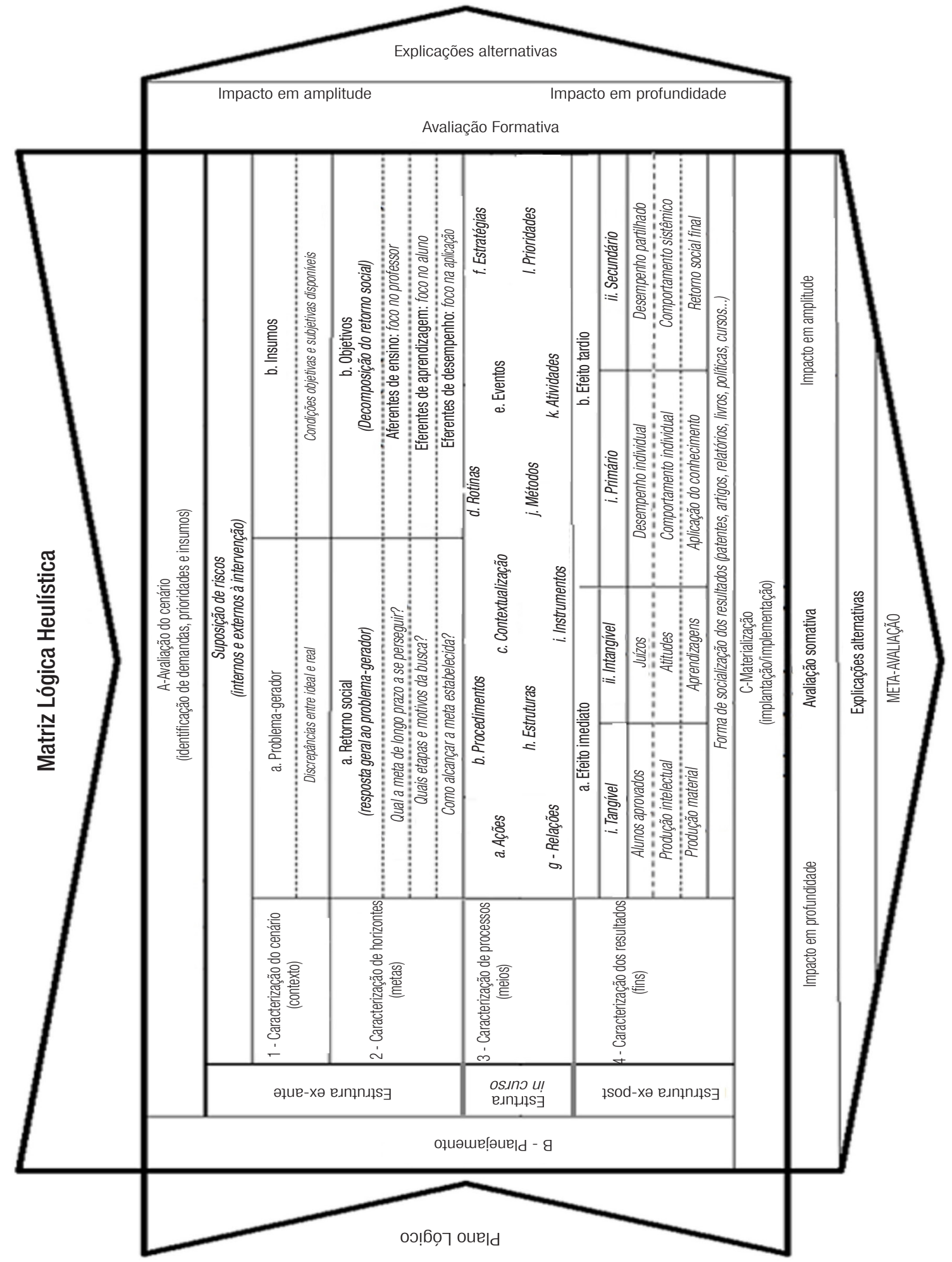

Fonte: Elaboração própria. 0 plano cronológico indica o sentido hierárquico de ocorrência das ações A, B e C e 1, 2, 3 e 4 . 0 plano lógico indica a concomitância da avaliação formativa em cada etapa e, na área de intersecção com a linha do tempo, o conteúdo dos componentes. 
0 instrumento orientador da análise dos planos de ensino, do projeto de curso, do regulamento do programa e das dissertações, para extração de objetivos, foi a própria matriz lógica heurística. Esse instrumento foi utilizado como um organizador gráfico avançado para a extração das informações contidas nesses documentos, sendo seus componentes utilizados como categorias de análise previamente determinadas (MAMEDE, 2016). No presente trabalho, a análise dos objetivos configurou-se como o interesse central sobre o qual nos debruçaremos nas próximas páginas, sempre os percebendo de forma integrada, organicamente, aos demais componentes da MLH, em uma perspectiva sistêmica. Vale ressaltar que os objetivos presentes explícita e implicitamente nas dissertações, ainda que construídos com foco na pesquisa proposta pelo mestrando e não no processo didático-pedagógico, nos permitiu identificar nos resultados, já obtidos e entendidos como resposta a expectativas dispersas no texto do plano de curso, elementos facilitadores do resgate de objetivos deste último documento, possibilitando seu melhor delineamento pelo confronto entre um documento que se localizava no início do processo e outro localizado no final. Muitas vezes, um documento reproduzia, reforçava ou complementava o que se encontrava presente no outro. Assim, os documentos foram lidos e, conforme o referencial teórico adotado, todos os elementos textuais entendidos como marcadores dos objetivos e expectativas do programa, ainda que incompletos, foram selecionados e agrupados nas categorias objetivos pedagógicos de ensino, objetivos pedagógicos de aprendizagem e objetivos pedagógicos de desempenho, como pode ser conferido à frente.

Quanto aos planos de ensino, uma segunda leitura sistemática, com o auxílio do Instrumento de Análise dos Planos de Ensino (Iape), foi realizada, com o intuito de caracterizar os objetivos ali presentes. O Iape foi constituído de 54 itens e mais dezenove subitens distribuídos em cinco categorias (objetivo geral, objetivos específicos, proposta metodológica de ensino-aprendizagem, fontes de informação e considerações gerais) e uma subcategoria (recurso de apoio). Para os limites do presente trabalho, apresentaremos os resultados referentes às categorias objetivo geral e objetivos específicos. Assim, com o instrumento em mãos, procedemos à leitura cuidadosa de cada um dos onze planos de ensino, preenchendo as colunas à direita de cada item com um X à medida que a leitura permitia identificar, no plano, o critério elencado no instrumento. Ao final, foi construída uma planilha-síntese que permitiu uma visão geral quantitativa das características do conjunto de planos de ensino, como é possível conferir adiante.

\section{Descrição e discussão dos resultados}

No escopo deste trabalho, adotamos uma variante das prescrições propostas por Sossai (1974), Ferraz e Belhot (2010), Mourão e Meneses (2012), Zerbini e colaboradores (2012), Martinez, Martinez e Toledo (2013) e Silva e Martins (2014), a partir de aportes da taxonomia de Bloom. Nessa perspectiva, assumimos que um objetivo pedagógico terá maior probabilidade de contribuir com a elaboração de um plano de ensino orgânico e efetivo quando obedecer a uma matriz de referência que vislumbre hierarquias 
taxonômicas como estratégia ao alcance de competências, indo ao encontro das proposições de Silva e Martins (2014).

A análise documental permitiu identificar que os objetivos explícitos do projeto de curso foram focados em atributos mais genéricos do processo de ensino-aprendizagem, ainda que buscasse contextualizá-los na realidade de serviço. Aqui, mais algumas questões merecem destaque. Os objetivos específicos, nesse documento, assumiram um perfil de aferência, característico de objetivos mais gerais e, se furtando a seguir as prescrições teóricas aqui adotadas (FERRAZ; BELHOT, 2010) ou não deixando clara sua filiação teórica quanto à forma de elaboração, não se mostraram precisos quanto à descrição em termos de desempenhos observáveis/esperados, bem como quanto aos verbos, sendo observada ausência de indicadores quali ou quantitativos para a avaliação de tais desempenhos. Isso tende a abrir espaço para o investimento em processos e produtos com interesses mais genéricos e acadêmicos ou desvinculados da realidade de serviço imediata do pesquisador, sem a especificidade esperada de um mestrado profissional, talvez refletindo um modelo centralizado de elaboração do projeto de curso e construção curricular (MAMEDE, 2016). Curiosamente, os objetivos presentes no art. 20 do Regulamento do Programa apresentaram-se melhor estruturados do que aqueles do projeto, contudo, não é esse o instrumento que regula e orienta a conduta pedagógica docente no curso, o que nos encaminhou para uma análise mais acurada dos objetivos do projeto de curso.

Tanto no plano de curso quanto nos planos de ensino a construção dos objetivos explícitos textualmente não foi rigorosa e clara quanto aos parâmetros e às condições para o alcance dos fins, que poderiam estar presentes como forma de delimitar e se avaliar melhor os resultados esperados. Lembramos que, em consonância com o referencial adotado no seio deste trabalho, parâmetro refere-se à existência de uma referência estabelecida (critérios, normas, padrões, pressupostos) para obtenção de um fim almejado, em termos de aferência ou eferência, enquanto condições corresponde à explicitação dos meios, motivos, lugar, prazo, circunscrição e estratégias constituídos pelos sujeitos da ação implícita na competência (fım) planejada, possibilitando a aferição de seu desenvolvimento em comportamentos observáveis.

Apesar de adotarmos as demais recomendações da nova taxonomia de Bloom, originada da revisão de 2001 (FERRAZ; BELHOT, 2010), por conveniência optamos no presente trabalho por manter os nomes das categorias como substantivos. Assim, seguindo as prescrições teóricas para a construção de objetivos e adotando os pressupostos aqui propostos, o objetivo geral apresentado no plano de curso poderia ficar como algo do tipo: qualificar, cientificamente, a força de trabalho em saúde [fim aferente], com ênfase na área de gestão dos sistemas e serviços de saúde [circunscrição], por meio de um curso de mestrado profissional [meio], com referência nos princípios do SUS [parâmetros]. 
Figura 2 - Objetivos emergentes da leitura do regulamento do programa, do plano de curso, dos planos de ensino e das dissertações e reelaborados conforme princípios da taxonomia de Bloom.

\section{LISTA DE OBJETIVOS}

\section{- Objetivos de ensino (modelo aferente: “esperamos que o programa seja capaz de...”)}

a) Otimizar os níveis de desempenho no serviço, por meio do fortalecimento da capacidade de gestão em Saúde (obj explícito no projeto)

b) Estimular a produção de novos conhecimentos nas áreas de abrangência do curso (obj explícito no projeto)

c) Aprimorar o Sistema de Saúde, por meio do desenvolvimento dos conhecimentos técnicos e científicos nesse campo (obj explícito no projeto) d) Qualificar a força de trabalho empregada no SUS (obj explícito no projeto)

\section{- Objetivos de aprendizagem (modelo eferente: “na sala de aula, 0 aluno será capaz de...”)}

a) Descrever os condicionantes e determinantes socioambientais da saúde

b) Identificar os principais conceitos e usos da Epidemiologia e sua aplicação na gestão de sistemas de Saúde c) Identificar a diferença entre promoção da saúde e prevenção de doenças

d) Demonstrar compreensão sobre os mecanismos de financiamento e o processo de descentralização do SUS e) Interpretar as normas e conceitos referentes à área da Saúde Coletiva e da Ciência

f) Interpretar os elementos teóricos e práticos da Política Nacional de Educação Permanente em Saúde

g) Demonstrar habilidade na busca de literatura científica para a elaboração de projetos e trabalhos de pesquisa

h) Correlacionar população, saúde e qualidade de vida, na formulação de teorias e hipóteses explicativas, a partir de aspectos quantitativos

i) Correlacionar os elementos de uma gestão estratégica com as novas modalidades de gestão das unidades estatais de Saúde

j) Correlacionar os elementos históricos da promoção da saúde e das políticas em Saúde no Brasil e América Latina com a situação do atual modelo de atenção à saúde do SUS

k) Correlacionar a situação da Saúde no Brasil com a formação do complexo médico industrial no WS Europeu

l) Criticar as bases teóricas e metodológicas da Metodologia da Problematização, na prática clínica, na pesquisa e no ensino, por meio da teoria do Arco de Maguerez

m) Elaborar projetos de pesquisa e textos de comunicação científica referentes à área da Saúde Coletiva

\section{• Objetivos de desempenho (modelo eferente: "no serviço, o egresso será capaz de...")}

a) Aplicar elementos e índices econômicos, na avaliação dos serviços de Saúde

b) Aplicar os princípios da Política Nacional de Educação Permanente em Saúde, em intervenções educativas na promoção da saúde e formação profissional

c) Empregar o contexto demográfico, cultural, político e econômico local e global, na formulação, implementação e avaliação de políticas e programas intersetoriais em Saúde

d) Utilizar os instrumentos de gestão e os sistemas de informação em Saúde, na programação da oferta de serviços e a avaliação das estratégias adotadas, em nível local e macro

e) Aplicar as normas e conceitos relativos à área da Saúde Coletiva e da Ciência, no desenvolvimento de projetos de pesquisa e textos de comunicação científica

f) Utilizar as bases de dados científicas, na formulação de propostas de intervenção e pesquisa no serviço

g) Aplicar o Arco de Maguerez, na implementação de estratégias de intervenção educativa em Saúde

h) Avaliar intervenções educativas, na promoção da saúde e formação profissional, por meio da crítica de seus princípios, a partir da Política Nacional de Educação Permanente em Saúde

i) Desenvolver formas de intervenção sobre os determinantes e condicionantes socioambientais da saúde, na estruturação de ambientes saudáveis.

Fonte: dados da pesquisa. 
Como o objetivo geral, os específicos necessitaram de adequação, mas não foi possível reescrevê-los de forma completa, em consonância com as prescrições teóricas, introduzindo o parâmetro e a condição para obtenção da competência, sob o risco de comprometer sua integridade e legitimidade pela ausência de dados fidedignos e pela incorporação de fatores clandestinos à proposição original que veiculam. Assim, pudemos perceber que muitos objetivos possiveis de serem explicitamente previstos no planejamento do programa e das disciplinas não o foram, o que demandou sua extração, ainda que sem todos os elementos ideais, a partir da leitura do regulamento, do projeto, dos planos de curso e das dissertações, o que, com os explícitos, originou uma lista de objetivos do programa (Figura 2). Lembramos que a leitura dos planos de ensino se deu em dois níveis: uma primeira leitura, orientada pela MLH (Figura 1), destinada à extração de objetivos julgados segundo a Tabela Bidimensional de Bloom (Figuras 3 e 4), e uma segunda leitura mais sistemática, por meio do cotejamento com o Iape (Figura 5), a fim de caracterizar o perfil dos objetivos lá presentes.

Tal lista, apenas sugestiva e não exaustiva, prescindiu de uma hierarquia rígida, sendo que seu conteúdo possui lastro estrito com os conteúdos expressos nos documentos analisados, sem necessidade de acréscimos fundados na teoria, o que poderia, em tese, suprir as lacunas identificadas, mas comprometer sua legitimidade. Tendo isso em mente e seguindo as orientações de Silva e Martins (2014), ao considerarmos a Tabela Bidimensional da Taxonomia de Bloom revisada, classificamos os novos objetivos emergentes da análise documental do MPSC, como se pode observar nas Figuras 3 e 4.

Figura 3 - Classificação bidimensional dos objetivos de aprendizagem do MPSC-UFG, segundo a taxonomia de Bloom revisada.

\begin{tabular}{|c|c|c|c|c|c|c|}
\hline \multicolumn{7}{|c|}{ Quadro de Classificação Bidimensional de Bloom } \\
\hline \multirow{2}{*}{$\begin{array}{c}\text { Natureza do } \\
\text { conhecimento }\end{array}$} & \multicolumn{6}{|c|}{ Processos do Domínio Cognitivo } \\
\hline & Conhecimento & Compreensão & Aplicação & Análise & Avaliação & Síntese \\
\hline Factual & $a, b, c$ & & & & & \\
\hline Conceitual & & $d, e, f$ & & $\mathrm{~h}, \mathrm{i}, \mathrm{j}, \mathrm{k}$ & I & \\
\hline Operacional & & & $g, m$ & & & \\
\hline Metacognitivo & & & & & & \\
\hline
\end{tabular}

Fonte: dados da pesquisa.

Figura 4 - Classificação bidimensional dos objetivos de desempenho do MPSC-UFG, segundo a taxonomia de Bloom revisada.

\begin{tabular}{|c|c|c|c|c|c|c|}
\hline \multicolumn{7}{|c|}{ Quadro de Classificação Bidimensional de Bloom } \\
\hline \multirow{2}{*}{$\begin{array}{c}\text { Natureza do } \\
\text { conhecimento }\end{array}$} & \multicolumn{6}{|c|}{ Processos do Domínio Cognitivo } \\
\hline & Conhecimento & Compreensão & Aplicação & Análise & Avaliação & Síntese \\
\hline \multicolumn{7}{|l|}{ Factual } \\
\hline Conceitual & & & $d, f$ & & h & i \\
\hline Operacional & & & $a, b, c, e, g$ & & & \\
\hline Metacognitivo & & & & & & \\
\hline
\end{tabular}

Fonte: dados da pesquisa. 
Em ambos os casos, percebemos lacunas tanto nas colunas, quanto nas linhas, o que nos encaminha para a conclusão de que mesmo as expectativas expressas nos documentos analisados não são capazes de contemplar a bidimensionalidade do instrumento na totalidade. Contudo, é de se destacar que os objetivos de aprendizagem possuem uma distribuição mais ampla em termos de natureza do conhecimento e processo cognitivo, dado que foram extraídos por meio de uma análise documental que os identificou dispersos no corpo do texto e a partir de vários documentos e não arrolados como objetivos explícitos do projeto de curso, a fim de que pudessem orientar a elaboração dos planos de ensino. Os objetivos de desempenho, por outro lado, apresentaram uma concentração na categoria aplicação, o que não se constitui surpresa, dada sua natureza. Contudo, como os de aprendizagem, não foram arrolados explicitamente na maioria dos documentos analisados, permanecendo como objetivos implícitos, e não alcançaram os níveis mais complexos dos processos e da natureza (síntese e metacognição). Dando continuidade, procedemos à reanálise dos planos de ensino, por meio do Iape, com resultados sintetizados na Figura 5.

Como vemos pela Figura 5, o maior número de marcações foi de critério ausente (286), o que indica algumas carências, como veremos adiante. Das onze disciplinas analisadas, cinco apresentaram o tópico objetivo geral. Sua estrutura ficou carente quanto às condições e parâmetros necessários ao alcance dos resultados almejados, os quais, quando presentes em três das disciplinas, foram pouco específicos, o que pode dificultar a avaliação do sucesso das metas. Foram utilizados os verbos analisar, capacitar, aplicar e refletir como indicadores da ação proposta. Ainda que não seja obrigatória a presença de tal tópico em um plano de ensino, quando está presente, é necessário deixar claro quem é o sujeito do verbo de ação, quando este não for evidente em si, seja pela anteposição de um caput como "0 curso visa..." (característico dos objetivos gerais) ou "Ao final do curso, o aluno será capaz de..." (próprio dos objetivos específicos), seja pela existência de uma orientação teórica clara no projeto de curso, o que não foi identificado. Nessa perspectiva, ficou pouco claro qual o objetivo geral almejado por alguns desses planos, pois analisar pode tanto ser uma competência relativa ao processo cognitivo análise (FERRAZ; BELHOT, 2010), quanto um método de aula aplicado pelo professor e sem relação com a competência esperada do aluno. 0 mesmo raciocínio pode ser aplicado a "aplicar" e "refletir", com a diferença de ser este último um verbo inespecífico quanto ao domínio de aprendizagem e ao processo cognitivo a que se refere. Por seu turno, "capacitar", no contexto em que foi utilizado, deixou claro ser seu sujeito o curso ou o docente, seguindo o modelo aferente, contudo, a estrutura geral do objetivo ficou confusa, por ligar o verbo a duas metas (uso de instrumentos de gestão e identificação de seus atributos) que representam duas competências e dois processos cognitivos distintos. 
Figura 5 - Instrumento de Análise dos Planos de Ensino (lape) com os resultados obtidos.

\begin{tabular}{|c|c|c|c|c|}
\hline \multicolumn{5}{|l|}{ Instrumento de Análise dos Planos de Ensino (lape) } \\
\hline \multirow{2}{*}{$\begin{array}{l}\text { Critérios de análise } \\
\text { A- OBJJTIVO GERAL: }\end{array}$} & \multicolumn{4}{|c|}{ Totalizações } \\
\hline & $E$ & & A: & $\mathrm{NI}$ \\
\hline 1) Definição dos fins esperados (ação e conteúdos da ação) & 0 & 5 & 5 & 1 \\
\hline 2) Definição dos meios a serem utilizados para alcance dos fins (condições, instrumentos, estratégias) & 0 & 0 & $\vdots 1 \vdots$ & 0 \\
\hline 3) Definição do critério de referência para alcance dos fins (parâmetros, circunscrição) & 3 & 0 & 7 & \\
\hline 4) Clareza de ações e conteúdos que explicitem a competência acadêmica almejada (objetivo eferente de aprendizagem) & 1 & 0 & 6 & 4 \\
\hline 5) Clareza de ações e conteúdos que explicitem a competência profissional almejada (objetivo eferente de desempenho) & & 0 & 7 & 3 \\
\hline 6) Uso de verbos que expressam ações, cujo sujeito é o elaborador/executor do plano (objetivo aferente) & 0 & 2 & 6 & \\
\hline 7) Uso de parâmetro qualitativo & 1 & 0 & $\vdots 10 \vdots$ & \\
\hline 8) Uso de parâmetro quantitativo & 0 & 0 & $11 \vdots$ & 0 \\
\hline B- OBJETIVOS ESPECIFICOS: & $E$ & & A : & $\mathrm{NI}$ \\
\hline 9) Definição dos fins esperados (ação e conteúdos da ação) & 1 & 10 & $\vdots 0$ & \\
\hline 10) Definição dos meios a serem utilizados para alcance dos fins (condições, instrumentos, estratégias) & 1 & 0 & $\vdots 10 \vdots$ & \\
\hline 11) Definição do critério de referência para alcance dos fins (parâmetros, circunscrição) & 5 & 0 & 6 & 0 \\
\hline 12) Clareza de ações e conteúdos que explicitem a competência acadêmica almejada (objetivo eferente de aprendizagem) & 1 & $\vdots 10$ & $\vdots 0$ & 0 \\
\hline 13) Clareza de ações e conteúdos que explicitem a competência profissional almejada (objetivo eferente de desempenho) & 1 & 0 & $10 \vdots$ & 0 \\
\hline 14) Uso de verbos que expressam ações, cujo sujeito é o elaborador/executor do plano (objetivo aferente) & 0 & 1 & $9:$ & 1 \\
\hline 15) Organização hierárquica de objetivos, conforme taxonomia de Bloom & 0 & 0 & $11 \vdots$ & \\
\hline 16) Elaboração de objetivos do domínio cognitivo com & & & & \\
\hline a) Referência em processos do nível 1 (Conhecimento) & 7 & 2 & $1 \vdots$ & \\
\hline b) Referência em processos do nível 2 (Compreensão) & 4 & 2 & $5:$ & \\
\hline c) Referência em processos do nível 3 (Aplicação) & 3 & 0 & 8 & 0 \\
\hline d) Referência em processos do nível 4 (Análise) & 8 & 0 & 3 & 0 \\
\hline e) Referência em processos do nível 5 (Avaliação) & 1 & 0 & 10 : & 0 \\
\hline f) Referência em processos do nível 6 (Síntese) & 1 & 0 & $10 \vdots$ & 0 \\
\hline g) Referência em conhecimentos de natureza factual & 8 & 2 & $1:$ & 0 \\
\hline h) Referência em conhecimentos de natureza conceitual & 8 & 2 & 1 & 0 \\
\hline i) Referência em conhecimentos de natureza operacional & 2 & 0 & 9 & 0 \\
\hline j) Referência em conhecimentos de natureza metacognitiva & 0 & 0 & $11 \vdots$ & 0 \\
\hline 17) Elaboração de objetivos do domínio afetivo com & & & & \\
\hline a) Referência em processos do nível 1 (Recepção) & 1 & 0 & $\vdots 10 \vdots$ & 0 \\
\hline b) Referência em processos do nível 2 (Resposta) & 0 & 0 & $\vdots 11 \vdots$ & 0 \\
\hline c) Referência em processos do nível 3 (Valoração) & 0 & 0 & 11 : & 0 \\
\hline d) Referência em processos do nível 4 (Organização) & 0 & 0 & $11:$ & 0 \\
\hline e) Referência em processos do nível 5 (Caracterização) & 0 & 0 & 10 & 1 \\
\hline \multicolumn{5}{|l|}{ 18) Elaboração de objetivos do domínio sensório-motor com } \\
\hline a) Referência em processos do nível 1 (Imitação) & 0 & 0 & 11 : & 0 \\
\hline b) Referência em processos do nível 2 (Manipulação) & 0 & 0 & $\vdots 11 \vdots$ & 0 \\
\hline c) Referência em processos do nível 3 (Articulação) & 0 & 0 & $\bar{\vdots} 11 \vdots$ & 0 \\
\hline d) Referência em processos do nível 4 (Naturalização) & 0 & 0 & $11 \vdots$ & 0 \\
\hline 19) Uso de parâmetro qualitativo & & & & \\
\hline \multicolumn{5}{|l|}{ 20) Uso de parâmetro quantitativo } \\
\hline TOTAL DE MARCAÇÕES POR VARIÁVEL & 58 & 36 & 286 & 16 \\
\hline
\end{tabular}

Fonte: dados da pesquisa. À direita de cada afirmativa, encontra-se o somatório de resultados correspondentes a cada critério utilizado, onde: "E" (existência), indica a presença do item no material em estudo, mas como uma característica inespecífica, genérica, parcial, discreta, acessória, secundária, casual ou obscura; "P" (predominância), indica a presença do item no material em estudo como uma característica dominante, marcante, explícita, importante, frequente ou clara; "A" (ausência) indica itens que não se encontram presentes neste material e "NI" (não identificado), indica itens a respeito dos quais não se obteve informações ou dados suficientes para formular conclusão. 
Como pode ser observado na transcrição abaixo, extraída de uma das disciplinas do curso, o verbo no gerúndio não remete à ideia de meio ou mesmo de circunscrição para alcance do fim expresso pelos verbos "capacitar" e "usar", o que daria organicidade e completude ao objetivo:

Capacitar discentes do Mestrado em Gestão de Sistemas e Serviços de Saúde quanto ao uso dos principais instrumentos de gestão adotados pelo SUS, identificando o seu desenvolvimento ao longo do processo de implementação do sistema, sua racionalidade, fins e aplicação práticas no contexto da gestão. (Grifos nossos) ${ }^{5}$.

Quanto aos objetivos específicos, todas as disciplinas os apresentaram. Na maioria das vezes, pareceu haver uma preocupação com o uso de verbos sugeridos pela taxonomia de Bloom (SOSSAI, 1974; FERRAZ; BELHOT, 2010), contudo, não pareceu haver a mesma preocupação com a hierarquização e sintaxe dos objetivos, que careceram de organicidade sequencial entre si e de elementos como condições e parâmetros ou, quando os apresentavam, eram muito genéricos. Além disso, em algumas disciplinas, por vezes, utilizaram-se verbos inespecíficos e menos operacionais (tais como dar, aproximar e sensibilizar), mais propriamente aceitáveis em objetivos gerais. $\mathrm{Na}$ maioria absoluta das vezes, foram utilizados verbos da taxonomia, mas ou em um contexto discursivo que remetia à ideia de aferência ou, como foi o caso de duas disciplinas, sem discriminar os diferentes domínios.

Com exceção de duas disciplinas, uma que utilizou um verbo do domínio afetivo (favorecer) e outra que utilizou um verbo que pode ser interpretado tanto como sendo do domínio afetivo quanto do sensório-motor (incorporar), inclusos em um mesmo grupo de objetivos cognitivos, as demais concentraram-se apenas no domínio cognitivo para a construção de seus objetivos. Também aqui, foi possível identificar, por vezes, duas metas, duas competências relacionadas com processos de aprendizagem diferentes, em um mesmo objetivo, comprometendo sua linearidade e dificultando a avaliação e o planejamento das aulas. Identificamos, ainda, uma predominância de objetivos relacionados ao processo cognitivo conhecimento, seguido, respectivamente, pelos níveis análise e aplicação, com uma distância pequena entre os dois primeiros e uma distância mais significativa entre estes e o último. Relação semelhante pode ser estabelecida no que se refere à natureza do conhecimento, havendo predominância absoluta dos tipos factual e conceitual. Tais dados, em se tratando de mestrados profissionais, dificultam o atendimento das expectativas de aplicabilidade do conhecimento expostas nas políticas públicas de flexibilização da pós-graduação (BRASIL, 2010), tornando-a um resultado contingencial e exclusivamente dependente do egresso, à semelhança do que é característico de mestrados acadêmicos.

Ainda que a presença de objetivos gerais não seja uma obrigatoriedade na elaboração de planos de aula e de ensino, sua existência é capaz de delinear os contornos da disciplina, em um complemento à ementa, e favorecer a seleção de conteúdos e a elaboração das estratégias metodológicas, dando sentido e contexto aos objetivos específicos (SOSSAI,

5- Plano de aula. 
1974). Assim, a fim de que tal organicidade do plano de ensino seja alcançada, tanto os objetivos gerais quanto os específicos necessitam seguir algumas prescrições teóricas e sugerimos as referências por nós utilizadas na presente investigação, por entendê-las úteis à superação dos problemas identificados.

\section{Considerações finais}

Falar de currículo e de aproximação entre o mundo escolar e o mundo do trabalho, como propõem as políticas de flexibilização da pós-graduação, nos traz à memória a importância de termos na realidade concreta extraescolar o referencial para a seleção, desenvolvimento e aplicação de conteúdos (FREIRE, 1987), bem como nos remete aos debates sobre o tradicionalismo pedagógico característico de nossas universidades (BORDENAVE; PEREIRA, 1983; ALMEIDA FILHO, 2011; VILLARDI; CYRINO; BERBEL, 2014) e sobre o não resolvido dilema, já trazido por Saviani (1981), entre a pedagogia tradicional e as tendências pedagógicas derivadas do escolanovismo (LIBÂNEO, 1985). Nesse sentido, a construção adequada de objetivos educacionais teoricamente fundamentados é um importante passo, pois nos permite orientar a prática pedagógica segundo pressupostos teóricos claros, identificar pontos de chegada e analisar resultados, avaliando sua eficácia e efetividade.

Os objetivos traçados para o curso nos documentos analisados do MPSC objeto da presente investigação apresentaram algumas falhas: ficaram pouco focados na realidade locorregionalizada ou pouco específicos com a função do egresso no cargo em sua instituição de origem, ainda que contextualizados dentro do PPSUS (Programa de Pesquisa para o SUS) ou da ANPPS (Agenda Nacional de Prioridades de Pesquisa em Saúde), e careceram de fundamentação teórica quanto às normas para sua elaboração, se apresentando muito genéricos, com uma estrutura diversificada (sem um padrão), que indica a ausência de uma linha teórica evidente e dificulta a avaliação da efetividade e da eficácia e a orientação da prática pedagógica. A construção de objetivos eferentes teoricamente fundados no referencial adotado neste trabalho permite o direcionamento orgânico de aulas e avaliações, contudo, deve se dar sem que descuremos aspectos culturais e psicológicos mais amplos, que estão implícitos e podem ser evidenciados na ementa e nos objetivos aferentes e são veiculados por meio das metodologias de aula e dos conteúdos, fornecendo referências para a construção de valores e princípios subjacentes à prática pedagógica, tornando a universidade uma instituição socializadora da profissão, com a função de, mais do que transmitir conteúdos e formar tecnicamente, conduzir seu egresso à adoção de atitudes, de forma que venha a pensar, agir e sentir em consonância com os preceitos éticos, políticos e filosóficos da profissão e da sociedade no decorrer de sua vida e não apenas dentro de sala de aula, como mencionam Nunes (2007) e Aquino (2008). 0 que nos parece evidente é que isso precisa ser entendido de forma ampliada e aplicada a todas as áreas de formação abraçadas pelos mestrados profissionais (e, talvez, não só por eles), de maneira a produzir uma profícua aproximação entre mundo acadêmico e mundo do trabalho, na direção de um meio-termo que supere 
a simples submissão de um ao outro e promova a flexibilização proposta pelas políticas mais amplas da pós-graduação.

A despeito de haver certo distanciamento entre as estratégias didáticas propostas nos planos de ensino e aquilo que se tem como expectativa nas políticas públicas para o mestrado profissional, existe no MPSC analisado alto grau de coerência interna a cada plano de ensino individualmente, evidenciado pela adequação entre os objetivos traçados e a metodologia de aulas descrita. Em que pese o fato de os objetivos apresentarem falhas, a coerência interna demonstra o potencial docente do programa para a implementação didática de uma proposta pedagógica a ser metodologicamente orientada por um plano de curso que esteja em sintonia com as expectativas depositadas pelo PNPG sobre o mestrado profissional. Mais que a necessária formação pedagógica do corpo docente, isso demanda um aprofundamento teórico sobre o que seja e o que se espera, de fato, de um curso de pós-graduação stricto sensu na modalidade profissional.

\section{Referências}

ABBAD, Gardênia da Silva et al. Planejamento instrucional em TD\&E. In: BORGES-ANDRADE, Jairo Eduardo; ABBAD, Gardênia da Silva; MOURÃ̃, Lucina. Treinamento, desenvolvimento e educação corporativa: fundamentos para a gestão de pessoas. Porto Alegre: Artmed, 2006. p. 289-321.

ALMEIDA FILHO, Naomar Monteiro de. Higher education and health care in Brazil. The Lancet, Londres, v. 377, n. 9781, p. 1898-1900, 2011. Disponível em: <http://www.thelancet.com/pdfs/journals/lancet/ PIIS0140-6736(11)60326-7.pdf>. Acesso em: 12 jul. 2012. Versão portuguesa disponível em: <http:// www.abc.org.br/IMG/pdf/doc-574.pdf>.

AQUINO, Estela Maria. Epidemiologia e saúde coletiva no Brasil: desafios para a formação em pesquisa. Revista Brasileira de Epidemiologia, São Paulo, v. 11, supl. 1, p. 151-158, 2008.

ARENDT, Hannah. A condição humana. 11. ed. Rio de Janeiro: Forense Universitária, 2010.

BARROS, Elionora Cavalcanti de; VALENTIM, Márcia Cristina; MELO, Maria Amélia Aragão. 0 debate sobre 0 mestrado profissional na Capes: trajetória e definições. Revista Brasileira de Pós-Graduação, Brasília, DF, v. 2, n. 4, p. 124-138, 2005. Disponível em: <http://ojs.rbpg.capes.gov.br/index.php/rbpg/issue/view/4>. Acesso em: 05 mar. 2014.

BENTO, José Olímpio. Do estado da universidade: metida num sarcófago ou no leito de Procrustes? Avaliação, Campinas, v. 19, n. 3, p. 689-721, 2014.

BORDENAVE, Juan Díaz; PEREIRA, Adair Martins. Estratégias de ensino-aprendizagem. 5. ed. Petrópolis: Vozes, 1983. 
BORGES-ANDRADE, Jairo Eduardo. Avaliação integrada e somativa em TD\&E. In: BORGES-ANDRADE, Jairo Eduardo; ABBAD, Gardênia da Silva; MOURÃO, Luciana (Org.). TD\&E em organizações e trabalho. Porto Alegre: Artmed, 2006. p. 343-358.

BORGES-ANDRADE, Jairo Eduardo. Desenvolvimento de medidas em avaliação de treinamento. Estudos de Psicologia, Natal, v. 7, n. esp., p. 31-43, 2002.

BRASIL. Conselho Superior da Coordenação de Aperfeiçoamento de Pessoal do Nível Superior. Programa de flexibilização do modelo de pós-graduação Senso Estrito em nível de mestrado (Boletim Informativo/1995). Documentos/RBPG, Brasília, DF, v. 2, n. 4, 2005, p. 45-146. Disponível em: <http://ojs.rbpg.capes.gov.br/ index.php/rbpg/article/viewFile/86/82>. Acesso em: 15 jul. 2014.

BRASIL. Parecer 977 de 03 de dezembro de 1965. Define os diferentes tipos de pós-graduação, informa sobre o contexto histórico de seu desenvolvimento no Brasil e em outros países, além de outras considerações. Câmara de Ensino Superior. Ministério da Educação. Diário Oficial da União de 20 de janeiro de 1966. Infocapes, Brasília, DF, v. 7, n. 4, p. 37-51, 1999. Disponível em: <http://www.capes.gov.br/ images/stories/download/bolsas/Info4_99.pdf>. Acesso em: 15 dez. 2011.

BRASIL. Plano Nacional de Pós-Graduação: (V PNPG 2011-2020). v. 1-2.Brasília, DF: Ministério da Educação: Capes, 2010. Disponível em: <http://www.capes.gov.br/component/content/article?id=4439>. Acesso em 15 ago. 2013.

BRASIL. Portaria Capes n. 17, de 28 de dezembro de 2009. Dispõe sobre o mestrado profissional no âmbito da Capes. Coordenação de Aperfeiçoamento de Pessoal de Nível Superior. Ministério da Educação. Diário Oficial de União, Brasília, DF, n. 248, 29 dez. 2009. Disponível em: <http://www.capes.gov.br/images/ stories/download/legislacao/PortariaNormativa_17MP.pdf>. Acesso em: 19 dez. 2012.

BRASIL. Portaria Capes n. 47 de 17 de outubro de 1995. Procedimentos apropriados à recomendação, acompanhamento e avaliação de cursos de mestrado dirigidos à formação profissional. Coordenação de Aperfeiçoamento de Pessoal do Nível Superior. Ministério da Educação. Documentos/RBPG, Brasília, DF, v. 2, n. 4, p. 47-148, jul. 2005. Disponível em: <http://www.foprof.org.br/documentos/portaria-no-4717-outubro-1995.pdf>. Acesso em: 15 jul. 2014.

CONTANDRIOPOULOS, André-Pierre et al. Avaliação na área da saúde: conceitos e métodos. In: HARTZ, Zulmira Maria de Araújo (Org.). Avaliação em saúde: dos modelos conceituais à prática na análise da implantação de programas. Rio de Janeiro: FioCruz, 1997. p. 49-88. Disponível em: <http://static.scielo. org/scielobooks/3zcft/pdf/hartz-9788575414033.pdf>. Acesso em: 12 jul. 2013.

DENIS, Jean-Louis; CHAMPAGNE, François. Análise da implantação. In: HARTZ, Zulmira Maria de Araújo (Org.). Avaliação em saúde: dos modelos conceituais à prática na análise da implantação de programas. Rio de janeiro: FioCruz, 1997. p. 49-88. Disponível em: <http://static.scielo.org/scielobooks/3zctt/pdf/ hartz-9788575414033.pdf>. Acesso em: 12 jul. 2013. 
FERRAZ, Ana Paula do Carmo Marcheti; BELHOT, RenatoVairo. Taxonomia de Bloom: revisão teórica e apresentação das adequações do instrumento para definição de objetivos instrucionais. Gestão \& Produção, São Carlos, v. 17, n. 2, p. 421-431, 2010. Disponível em: <http://www.scielo.br/pdf/gp/v17n2/ a15v17n2. pdf.>. Acesso em: 05 mar. 2015.

FREIRE, Paulo. Pedagogia do oprimido. 17. ed. Rio de Janeiro: Paz e Terra, 1987.

HAMBLIN, Anthony Crandell. Avaliação e controle do treinamento. São Paulo: McGraw-Hill do Brasil, 1978.

LABURÚ, Carlos Eduardo; ARRUDA, Sérgio de Mello; NARDI, Roberto. Pluralismo metodológico no ensino de ciências. Ciência \& Educação, Bauru, v. 9, n. 2, p. 247-260, 2003.

LIBÂNEO, José Carlos. Democratização da escola pública: a pedagogia crítico-social dos conteúdos. São Paulo: Loyola, 1985.

MAMEDE, Walner. Modelo para a avaliação de mestrados profissionais orientados à formação de recursos humanos para o SUS: um estudo de caso. 2016. Tese. (Doutorado em Ensino na Saúde) - Instituto de Psicologia da Universidade de Brasília, Brasília, DF, 2016.

MAMEDE, Walner. 0 mestrado profissional brasileiro e o mestrado em saúde pública europeia: objetivos semelhantes por caminhos diferentes. Revista Brasileira de Pós-Graduação, Brasília, DF, v. 12, n. 27, p. 147-169, 2015. Disponível em: <http://ojs.rbpg.capes.gov.br/index.php/rbpg/article/view/545/pdf>. Acesso em: 19 dez. 2015.

MARTINEZ, Armando Martínez; MARTINEZ, Deysi Miranda; TOLEDO, Yamilka Crespo. Abraham Flexner, Benjamin Bloom y Fidel llizástigui Dupuy: paradigmas de la educación médica americana. Revista de Ciencias Médicas de Pinar del Río, Pinar del Río, v. 17, n. 6, p. 202-216, 2013.

MELO, Kátia Valéria Araújo; OLIVEIRA, Rezilda Rodrigues. Origens e desenvolvimento institucional de um mestrado profissional. Revista Brasileira de Pós-Graduação, Brasília, DF, v. 2, n. 4, p. 105-123, 2005.

MOURÃO, Luciana; MENESES, Pedro Paulo Murce. Marco lógico como ferramenta de avaliação em TD\&E. In: ABBAD, Gardênia da Silva; MOURÃO, Luciana (Org.). Medidas de avaliação em TD\&E: ferramentas para gestão de pessoas. Porto Alegre: Artmed, 2012. p. 38-47.

NUNES, Everardo Duarte. Merton e a sociologia médica. História, Ciências, Saúde, Manguinhos, v. 14, n. 1, p. $159-172,2007$.

OLIVEIRA, Francisco José Arsego. Participação popular em saúde: as dimensões da cultura. Saúde em Debate, Londrina, n. 52, p. 67-73, 1996. Disponível em: <http://docvirt.com/asp/acervo_cebes. asp?Bib=SAUDEDEBATE\&PASTA=N.52+-+set.+1996\&pesq=Participa\%E7\%E30+Popular+em+Sa\%FA de\%3A+as+dimens\%F5es+da+cultura\&x=90\&y=9 > . Acesso em: 12 jul. 2014. 
OLIVEIRA, Rodrigo Maia; VELHO, Léa. Benefícios e riscos da proteção e comercialização da pesquisa acadêmica: uma discussão necessária. Ensaio, Rio de Janeiro, v. 17, n. 62, p. 25-54, 2009. Disponível em: <http://www.scielo.br/pdf/ensaio/v17n62/a03v1762.pdf>. Acesso em: 12 jul. 2014.

PEREIRA, Isabel Brasil; LIMA, Júlio César França. Educação profissional em saúde. In: PEREIRA, Isabel Brasil; LIMA, Júlio César França (Coord.). Dicionário da educação profissional em saúde. 2. ed. Rio de Janeiro: Fundação Oswaldo Cruz: Escola Politécnica de Saúde Joaquim Venâncio, 2009. p. 126-134. Disponível em: <http://www.epsjv.fiocruz.br/dicionario/verbetes/eduprosau.html>. Acesso em: 05 mar. 2015.

QUARESMA, Adilene Gonçalves; MACHADO, Lucília Regina de Souza. Questões pedagógicas do mestrado profissional: uma aproximação ao tema a partir de análises bibliográficas. Revista Brasileira de PósGraduação, Brasília, DF, v. 11, n. 24, p. 461-481, 2014.

RIBEIR0, Cláudio Rezende. A universidade como disputa da reprodução social: contribuição ao debate sobre os mestrados profissionais. Revista Brasileira de Pós-Graduação, Brasília, DF, v. 7, n. 14, p. 433-450, 2010.

RIBEIR0, Renato Janine. 0 mestrado profissional na política atual da Capes. Revista Brasileira de PósGraduação, Brasília, DF, v. 2, n. 4, p. 08-15, 2005.

RODRIGUES JR, José Florêncio. Taxonomias de objetivos em TD\&E. In: BORGES-ANDRADE, Jairo Eduardo; ABBAD, Gardênia da Silva (Org.). TD\&E em organizações e trabalho. Porto Alegre: Artmed, 2006. p. 282-288.

ROSA, Walisete de Almeida Godinho; LABATE, Renata Curi. Programa Saúde da Família: a construção de um novo modelo de assistência. Revista Latino-Americana de Enfermagem, Ribeirão Preto, v. 136, p. 10271034, 2005.

SAVIANI, Dermeval. Escola e democracia ou a teoria da curvatura da vara. ANDE, São Paulo, v. 1, n. 1, p. 23-33, 1981.

SCRIVEN, Michael. Evaluation thesaurus. 4. ed. Newbury Park: Sage, 1991.

SILVA, Vailton Afonso; MARTINS, Maria Inês. Análise de questões de física do ENEM pela taxonomia de Bloom revisada. Revista Ensaio, Belo Horizonte, v. 16, n. 3, p. 189-202, 2014. Disponível em: <http://www. scielo.br/pdf/epec/v16n3/1983-2117-epec-16-03-00189.pdf>. Acesso em: 19 dez. 2015.

SILVEIRA, Vladmir Oliveira da; PINTO, Felipe Chiarello de Souza. Reflexões necessárias sobre o mestrado profissional. Revista Brasileira de Pós-Graduação, Brasília, DF, v. 2, n. 4, p. 38-47, 2005.

SOSSAI, João Alvécio. Determinação de objetivos educativos. Revista de Saúde Pública, São Paulo, v. 8, n. 4, p. 437-442, 1974. Disponível em: <http://www.scielo.br/pdf/rsp/v8n4/09.pdf>. Acesso em: 13 jan. 2015. 
SOUZA, Danilea Borges Lima de. Avaliação de impacto do mestrado profissional multidisciplinar em desenvolvimento e gestão social. 2013. Tese. (Doutorado em Psicologia) - Instituto de Psicologia da Universidade de Brasília, Brasília, DF, 2013.

VILLARDI, Marina Lemos; CYRINO, Eliana Goldfarb; BERBEL, Neusi Aparecida Navas. A metodologia da problematização no contexto da formação em saúde. In: CYRINO, Antonio Pithon; GODOY, Daniele; CYRINO, Eliana Goldfarb (Org.). Saúde, ensino e comunidade: reflexões sobre práticas de ensino na atenção primária. São Paulo: Cultura Acadêmica, 2014. p. 147-189.

ZERBINI, Thaís et al. Transferência de treinamento e impacto do treinamento em profundidade. In: ABBAD, Gardênia da Silva et al. (Org.). Medidas de avaliação em TD\&E: ferramentas para a gestão de pessoas. Porto Alegre: Artmed, 2012. p. 127-146.

Recebido em: 26.09.2016

Aprovado em: 07.12.2016

Walner Mamede é doutor em ensino na saúde pela Universidade de Brasília (UNB) e trabalha na Coordenação Geral de Acompanhamento e Monitoramento de Resultados (CGMR) da Coordenação de Aperfeiçoamento de Pessoal de Nível Superior (Capes).

Gardênia S. Abbad é doutora em psicologia e docente pelo Instituto de Psicologia da Universidade de Brasília (UNB). 